\title{
Apoptosis inducing ability of silver decorated highly reduced graphene oxide nanocomposites in A549 lung cancer
}

This article was published in the following Dove Press journal:

International Journal of Nanomedicine

7 March 2016

Number of times this article has been viewed

\author{
Merajuddin Khan' \\ Mujeeb Khan' \\ Abdulhadi H Al-Marri' \\ Abdulrahman Al-Warthan' \\ Hamad Z Alkhathlan' \\ Mohammed Rafiq $\mathrm{H}$ \\ Siddiqui' \\ Vadithe Lakshma Nayak ${ }^{2}$ \\ Ahmed Kamal ${ }^{2}$ \\ Syed F Adil \\ 'Department of Chemistry, College \\ of Science, King Saud University, \\ Riyadh, Kingdom of Saudi Arabia; \\ ${ }^{2}$ Department of Medicinal Chemistry \\ and Pharmacology, CSIR - Indian \\ Institute of Chemical Technology, \\ Hyderabad, India
}

\begin{abstract}
Recently, graphene and graphene-based materials have been increasingly used for various biological applications due to their extraordinary physicochemical properties. Here, we demonstrate the anticancer properties and apoptosis-inducing ability of silver doped highly reduced graphene oxide nanocomposites synthesized by employing green approach. These nanocomposites (PGE-HRG-Ag) were synthesized by using Pulicaria glutinosa extract (PGE) as a reducing agent and were evaluated for their anticancer properties against various human cancer cell lines with tamoxifen as the reference drug. A correlation between the amount of $\mathrm{Ag}$ nanoparticles on the surface of highly reduced graphene oxide (HRG) and the anticancer activity of nanocomposite was observed, wherein an increase in the concentration of Ag nanoparticles on the surface of HRG led to the enhanced anticancer activity of the nanocomposite. The nanocomposite PGE-HRG-Ag-2 exhibited more potent cytotoxicity than standard drug in A549 cells, a human lung cancer cell line. A detailed investigation was undertaken and Fluorescence activated cell sorting (FACS) analysis demonstrated that the nanocomposite PGE-HRG-Ag-2 showed G0/G1 phase cell cycle arrest and induced apoptosis in A549 cells. Studies such as, measurement of mitochondrial membrane potential, generation of reactive oxygen species (ROS) and Annexin V-FITC staining assay suggested that this compound induced apoptosis in human lung cancer cells.
\end{abstract}

Keywords: plant extract, graphene/silver nanocomposites, anticancer, apoptosis

\section{Introduction}

The emergence of multi-drug resistance in different diseases has raised the challenge of their treatment to a newer level and has led to more focused research endeavors toward finding newer agents with the desired biological properties. Among them, the research on the cancer treatment has been more emphasized due to the growing number of diagnosed cases as well as mortality, with cancer being the second leading cause of death among patients throughout the world. ${ }^{1}$ Apoptosis, the programmed cell death, is an important process for the normal functioning of cells. In cancer, the mutated cells go unregulated by apoptosis and result in unchecked cell multiplication. Agents inducing or promoting apoptotic cell death are one of the important cornerstones in anticancer drug development.

Natural product-based organic molecules are one of the major sources of anticancer drug development ${ }^{2,3}$ and in recent years the conjugation of two pharmacophoric units has shown promising results. However, the medicinal use of metal-containing ointments/drugs is also very popular and known to humans since ages as described in the Papyus Ebers in $\sim 1550$ BC. ${ }^{4}$ Coordination complex of ligands to a metal is 


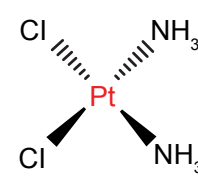

Cisplatin

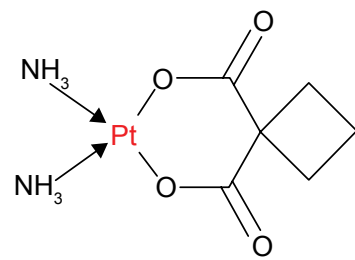

Carboplatin

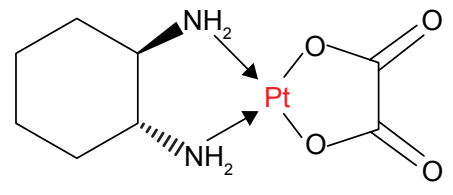

Oxaliplatin

Figure I Platinum $(\mathrm{Pt})$-containing anticancer drugs.

reported to provide numerous advantages, such as facilitating the sustained release of the ligands in the body resulting in longer-acting drugs ${ }^{5}$ and improving the bioactivity of the ligands. ${ }^{6,7}$ Cisplatin, carboplatin, and oxaliplatin are a few renowned examples from this class as shown in Figure $1 .^{8}$

Recently, it has been observed that there is a significant shift toward employing graphene-based nanocomposites in biological applications wherein they have been used as antibacterial agents and antifungal agents..$^{9-11}$ Additionally, it has also been reported to be employed in anticancer drug development as drug-carrier agents, ${ }^{10,12-14}$ for sustained release of drugs. For instance, in several studies on the delivery of the anticancer drug doxorubicin, it has been revealed that graphene oxide (GRO) played an effective role in the delivery and release of the drug into the targeted cancer cell. ${ }^{15,16}$

Apart from this, several other studies have also been published regarding the applications of graphene and graphene-based materials for various biological purposes due to their extraordinary physicochemical properties, such as mechanical properties, electrical properties, electrochemical properties, and thermal conductivity. ${ }^{14,17-24}$ However, despite the recent surge in such studies, a lot more needs to be done in order to fully exploit the potential of graphene-based materials in biological applications. ${ }^{25-27}$ Among the various challenges, the biocompatibility and toxicity of graphenebased materials both at in vitro and in vivo levels is one of the major challenges. ${ }^{17}$ Several factors define the toxicity of these materials one of them is the use of hazardous chemicals employed in the synthesis of graphene-based materials, which needs special attention ${ }^{14}$ towards their removal procedures for post-synthesis purification, which is one of the most important factors to conclude the biocompatibility of these materials.

Commonly, graphene-based materials are prepared by chemical methods in which the reagents involved in the preparation and functionalization of these materials are hazardous and harmful to both environment and human well-being due to their high toxicity. ${ }^{28}$ Additionally, trace amounts of toxic-reducing agents present on the surface of these materials could seriously affect the potential properties of highly reduced graphene oxide (HRG) and have undesirable effects on its biological applications. ${ }^{16}$ Whereas, the green synthesis of graphene-based materials involves biocompatible ingredients under physiological conditions of temperature and pressure. ${ }^{29,30}$ Among various methods, plant extract (PE)-based syntheses of graphene and graphene-based materials have attracted significant attention due to their bulk availability, biocompatibility, and low cost. ${ }^{31}$ Furthermore, the biologically active molecules employed in the synthesis of nanomaterials, particularly phytomolecules, which exist in the PE, often play the role of functionalizing ligands, thereby impeding the usage of any external chemical stabilizers. ${ }^{32}$

In our previous study, we have demonstrated a facile, single-step green approach for the synthesis of graphene/Ag nanocomposites (PGE-HRG-Ag) via in situ reduction of both GRO and silver ions using Pulicaria glutinosa extract (PGE) as a reducing agent. ${ }^{33}$ The phytomolecules of the PGE not only functionalize the surface of the HRG but also facilitate conjugation of Ag nanoparticles (NPs) on the surface of HRG. In order to demonstrate the significance of the green synthesized PGE-HRG-Ag nanocomposite in the biological applications and in continuation of our studies toward development of more potent anticancer agents, ${ }^{34-37}$ we investigated the in vitro anticancer activity of PGE-HRG-Ag nanocomposites (Figure 2). The anticancer evaluation studies of the as-prepared PGE-HRG-Ag nanocomposites were performed against various human cancer cell lines, including MCF-7 (breast), A549 (lung), Hela (cervical), DU-145 (prostate), and HepG2 (liver) using MTT study, while tamoxifen was used as the reference drug. Moreover, to the best of our knowledge, the anticancer properties of graphene/silver nanocomposite are being investigated for the first time.

\section{Experimental section Materials}

Graphite (99.999\%, -200 mesh) was purchased from (Alfa Aesar, Ward Hill, MA, USA). Concentrated sulfuric acid 


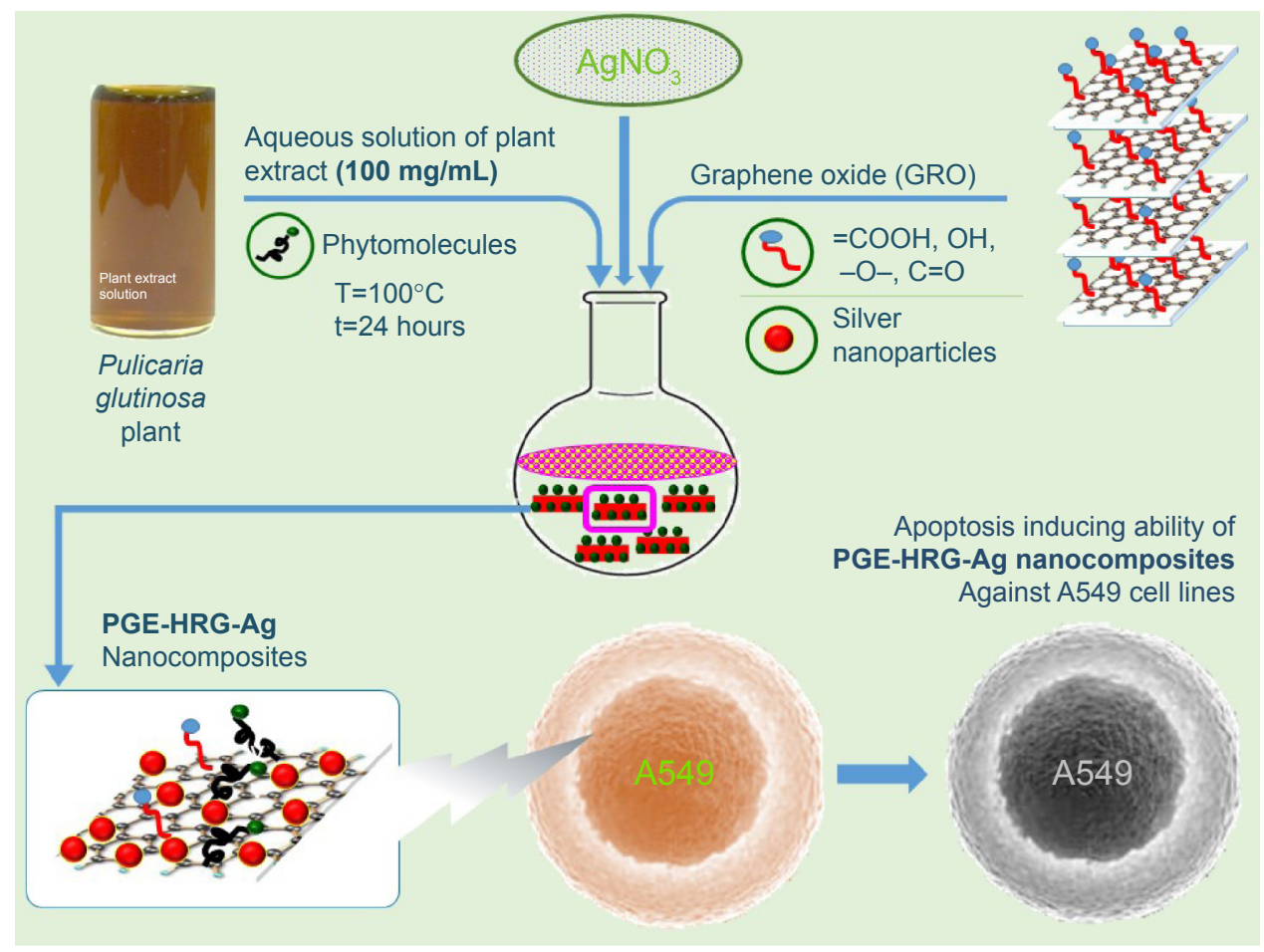

Figure 2 Graphical representation of the green synthesis of graphene/silver (PGE-HRG-Ag) nanocomposites using Pulicaria glutinosa plant extract and their anticancer activities against various human cancer cell lines.

Abbreviations: $\mathrm{T}$, temperature, $\mathrm{t}$, time.

$\left(\mathrm{H}_{2} \mathrm{SO}_{4}\right.$, molecular weight 98.079 [98\%]), potassium permanganate $\left(\mathrm{KMnO}_{4}\right.$, molecular weight 158.034 [99\%]), sodium nitrate $\left(\mathrm{NaNO}_{3}\right.$, molecular weight 84.9947 [99\%]), hydrogen peroxide $\left(\mathrm{H}_{2} \mathrm{O}_{2}\right.$, molecular weight 34.0147 [30 wt\%]), and all other solvents were purchased from (Aldrich chemicals, St Louis, MO, USA).

$P$. glutinosa, a wild plant growing in the hilly regions of Al-Hair in the central part of Kingdom of Saudi Arabia, was collected during March 2011, which was recognized and ascertained by a plant taxonomist from the Herbarium Division, College of Science, King Saud University, Riyadh, Kingdom of Saudi Arabia. The details of the plant and preparation of the PE are given elsewhere. ${ }^{38}$ The PE solution, employed for the reduction of GRO, was made using $0.1 \mathrm{~g}$ of PE dissolved in $1 \mathrm{~mL}$ of solvent.

\section{Synthesis and characterization of HRG/ Ag nanocomposites (PGE-HRG-Ag)}

Graphite oxide (GO) was synthesized from graphite powder by a modified Hummers method..$^{39,40}$ The as-prepared GO was further treated to obtain the desired nanocomposites by varying the concentration of silver NPs. To begin with, $1 \mathrm{~g}$ of natural graphite and $0.875 \mathrm{~g}$ of $\mathrm{NaNO}_{3}$ were taken in a three-neck round bottom flask. To this mixture, $150 \mathrm{~mL}$ of $\mathrm{H}_{2} \mathrm{SO}_{4}$ was added gently. The mixture was kept stirred for the next 2 hours in an ice-water bath; subsequently, $4.5 \mathrm{~g}$ of $\mathrm{KMnO}_{4}$ was added slowly in a period of 2 hours with constant stirring. The resulting mixture was allowed to stir for the next 5 days at room temperature. Afterwards, $100 \mathrm{~mL}$ of $5 \mathrm{wt} \% \mathrm{H}_{2} \mathrm{SO}_{4}$ aqueous solution was gradually added in 1 hour and the mixture was allowed to stir for another 2 hours. Thereafter, $3 \mathrm{~g}$ of $30 \mathrm{wt} \%$ aqueous solution of $\mathrm{H}_{2} \mathrm{O}_{2}$ was added, and the mixture was again left for stirring for another 2 hours. Finally, the resulting solution was washed with an aqueous solution of $3 \mathrm{wt} \% \mathrm{H}_{2} \mathrm{SO}_{4}$ and $0.5 \mathrm{wt} \% \mathrm{H}_{2} \mathrm{O}_{2}$ several times. A similar process was repeated with deionized water (DI) for three more times. The resulting mixture was dispersed in DI water and centrifuged for 2 hours at $9,000 \times g$. The dispersion was washed extensively ( $\sim 20$ times) with DI water until a homogeneous brown-black dispersion was obtained. ${ }^{33}$

\section{Synthesis of HRG/Ag nanocomposites (PGE-HRG-Ag)}

GRO required for the preparation of PGE-HRG-Ag was obtained by dispersing $170 \mathrm{mg}$ of as-prepared GO in $50 \mathrm{~mL}$ of distilled water under constant sonication for 30 minutes. The graphene/silver nanocomposite with $50 \mathrm{wt} \%$ of graphene (PGE-HRG-Ag-1) was prepared by taking $170 \mathrm{mg}$ aqueous dispersion of GRO and $0.5 \mathrm{mM}(84.93 \mathrm{mg})$ of $\mathrm{AgNO}_{3}$. The 
reaction mixture was prepared by taking $50 \mathrm{~mL}$ aqueous dispersion of GRO in a $250 \mathrm{~mL}$ round bottom flask. To this dispersion, separately prepared $50 \mathrm{~mL}$ aqueous solution of $\mathrm{AgNO}_{3}$ was added. The reaction mixture was allowed to stir for several minutes ( 10 minutes), and subsequently, to this mixture, $10 \mathrm{~mL}$ aqueous solution of $P$. glutinosa $\mathrm{PE}$ was added. The resulting mixture was heated up to $90^{\circ} \mathrm{C}$ and was kept under stirring for 24 hours. Afterwards, the mixture was allowed to cool down and washed several times (three to four times) with DI. Finally, $180 \mathrm{mg}$ of black powder was obtained after centrifugation. PGE-HRG was also prepared by a similar method without using $\mathrm{AgNO}_{3}$.

\section{Characterization}

The formation of as-synthesized GO and PGE-HRG-Ag was confirmed by several techniques, including, UV-Vis spectroscopy (PerkinElmer lambda 35 [Waltham, MA, USA]), high-resolution transmission electron microscopy (JEM 1101 [JEOL, Tokyo, Japan]), XRD (D2 Phaser X-ray diffractometer [Bruker Optik GmbH, Ettlingen, Germany]), $\mathrm{Cu} \mathrm{K} \alpha$ radiation $(\lambda=1.5418 \AA)$, and Raman spectroscopy (Renishaw, Gloucestershire, UK) equipped with a $514.5 \mathrm{~nm}$ line of argon ion laser as excitation source.

\section{Anticancer activity}

Nanocomposites (PGE-HRG-Ag-1 and -2) were evaluated for their anticancer activity in a panel of five human cancer cell lines, namely, MCF-7 (breast), A549 (lung), Hela (cervical), DU-145 (prostate), and HepG2 (liver) using MTT method, ${ }^{41}$ in which tamoxifen was used as a reference drug. The results are summarized in Table 1 and expressed as $\mathrm{IC}_{50}$ values. The studies were carried out on the cell lines procured from NCCS, Pune-India. The Indian Institute of Chemical Technology, Hyderabad, India, waived the requirement to obtain formal ethical approval for commercial cell lines.

\section{Cell cycle analysis}

FACS experiment was done to evaluate the cell cycle analysis. In this experiment, cells (A549) were treated with

Table I $\quad \mathrm{IC}_{50}$ values $^{\mathrm{a}}$ (in $\mu \mathrm{g}$ ) for compounds PGE-HRG-Ag-I and -2 in human cancer cell lines

\begin{tabular}{llllll}
\hline Compound & MCF-7 $^{\mathbf{b}}$ & Hela $^{\mathbf{c}}$ & HepG2 $^{\mathbf{d}}$ & A549 $^{\mathrm{e}}$ & DU-145 \\
\hline PGE-HRG-Ag-I & $>100(102.6)$ & 66.06 & 38.01 & 19.49 & 25.11 \\
PGE-HRG-Ag-2 & 31.62 & 33.11 & 40.00 & 9.638 & 14.96 \\
Tamoxifen & 9.015 & 19.95 & 10.96 & 11.22 & 14.12 \\
\hline
\end{tabular}

Notes: ${ }^{a} 50 \%$ inhibitory concentration after 48 hours of drug treatment. 'Human breast cancer. 'Human cervical cancer. ${ }^{d}$ Human liver cancer. eHuman lung cancer. fHuman prostate cancer. nanocomposite PGE-HRG-Ag-2 at concentrations of 5 and $10 \mu \mathrm{g}$. After treatment, cells were harvested and washed with phosphate-buffered saline (PBS). The pellets were fixed with ice-cold $70 \%$ ethanol followed by staining with propidium iodide (Sigma-Aldrich Co., St Louis, MO, USA). Flow cytometry was performed using Becton Dickinson FACS Caliber instrument (Becton, Dickinson and Company, Franklin Lakes, NJ, USA). ${ }^{42}$

\section{Measurement of $\Delta \Psi \mathrm{m}$}

Cells (A549) were cultured and seeded in 6-well plates. After plating, cells were treated with nanocomposite PGEHRG-Ag- 2 at 5 and $10 \mu \mathrm{g}$ concentrations for 48 hours. Cells were collected and washed with PBS. The washed cells were stained with JC-1 (5 $\mu \mathrm{g} / \mathrm{mL})$ and incubated at $37^{\circ} \mathrm{C}$ for 15 minutes. After incubation with JC-1, cells were then subjected to flow cytometric analysis on a flow cytometer (Becton Dickinson) in the FL1 and FL2 channels to detect mitochondrial potential. ${ }^{43}$

\section{Effect on intracellular ROS generation}

Reactive oxygen species (ROS) was measured by flow cytometry using $2^{\prime}, 7^{\prime}$ dichlorofluorescindiacetate (DCFDA) as previously described. ${ }^{44}$ A549 cells were treated with nanocomposite PGE-HRG-Ag-2 at 5 and $10 \mu \mathrm{g}$ concentrations for 48 hours. The treated cells were stained with DCFDA $(2 \mu \mathrm{M})$ at $37^{\circ} \mathrm{C}$ for 30 minutes and then measured with the flow cytometer (FACS).

\section{Annexin V-FITC for apoptosis}

An amount of $1 \times 10^{6}$ A549 cells was seeded in 6-well plates followed by treatment with nanocomposite PGE-HRG-Ag-2 at 5 and $10 \mu \mathrm{g}$ concentrations. Afterwards, the cells were washed with PBS at 3,000 rpm, and then flow cytometry was performed using Annexin-V-FITC apoptosis detection kit (Sigma-Aldrich) as described earlier. ${ }^{45}$

\section{Results and discussion}

The phytomolecule-rich PE of P. glutinosa when added to a dispersion of GRO and $\mathrm{AgNO}_{3}$ reduces both $\mathrm{Ag}$ ions and GRO simultaneously resulting in the formation of PGEHRG-Ag nanocomposites. By varying the concentration of $\mathrm{AgNO}_{3}$, two different samples of PGE-HRG-Ag nanocomposites, namely, PGE-HRG-Ag-1 and -2 were prepared using 0.5 and $1 \mathrm{mmol}$ of $\mathrm{AgNO}_{3}$, respectively, and the effect of this concentration on the anticancer and apoptosis-inducing ability of the nanocomposites was studied. The formation of these nanocomposites was examined by Ultraviolet-visible 

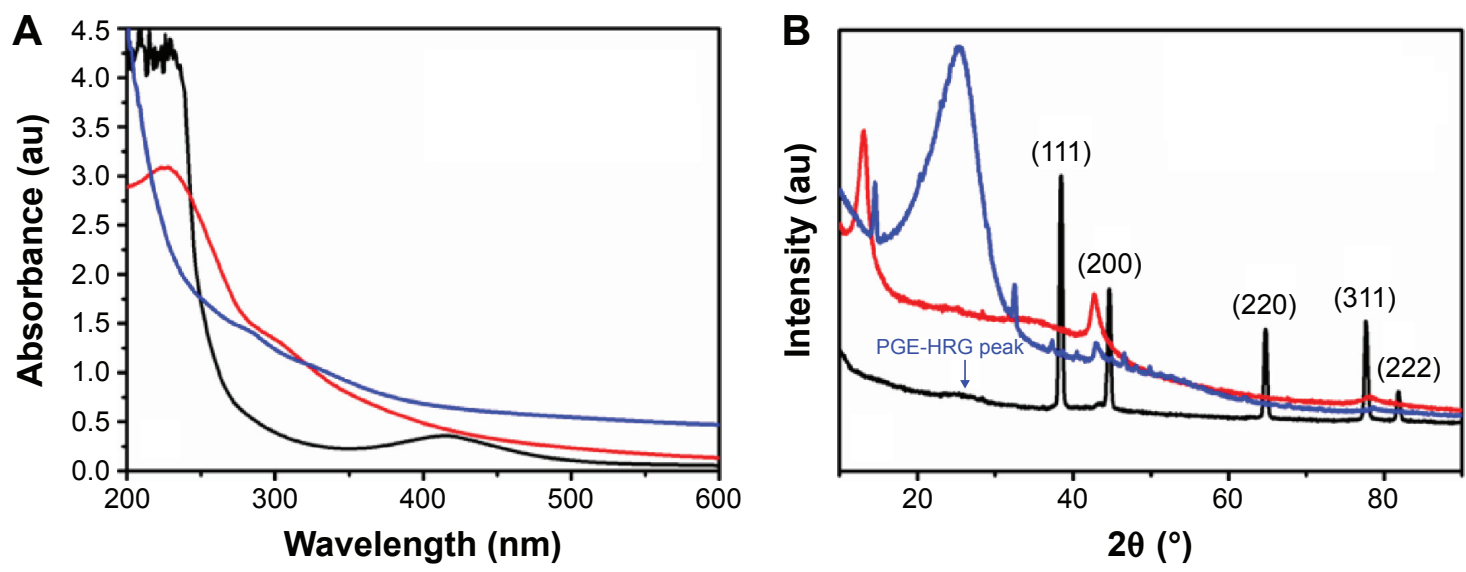

- GRO — PGE-HRG — PGE-HRG-Ag

Figure 3 (A) UV-Vis absorption spectra of GRO, PGE-HRG, and PGE-HRG-Ag; (B) XRD spectra of GRO, PGE-HRG, and PGE-HRG-Ag nanocomposites. Abbreviation: GRO, graphene oxide.

spectroscopy (UV-Vis) and the nanocomposites were subjected to an X-ray powder diffraction (XRD) analysis to confirm their crystalline nature (Figure 3). The characteristic reflections in the diffractogram suggested the complete reduction of GO employing PE. The samples were further characterized by Raman spectroscopy. The PGE-HRG without Ag NPs exhibits two Raman signals at 1,582 and $1,343 \mathrm{~cm}^{-1}$, respectively, as shown in Figure 4. These signals which

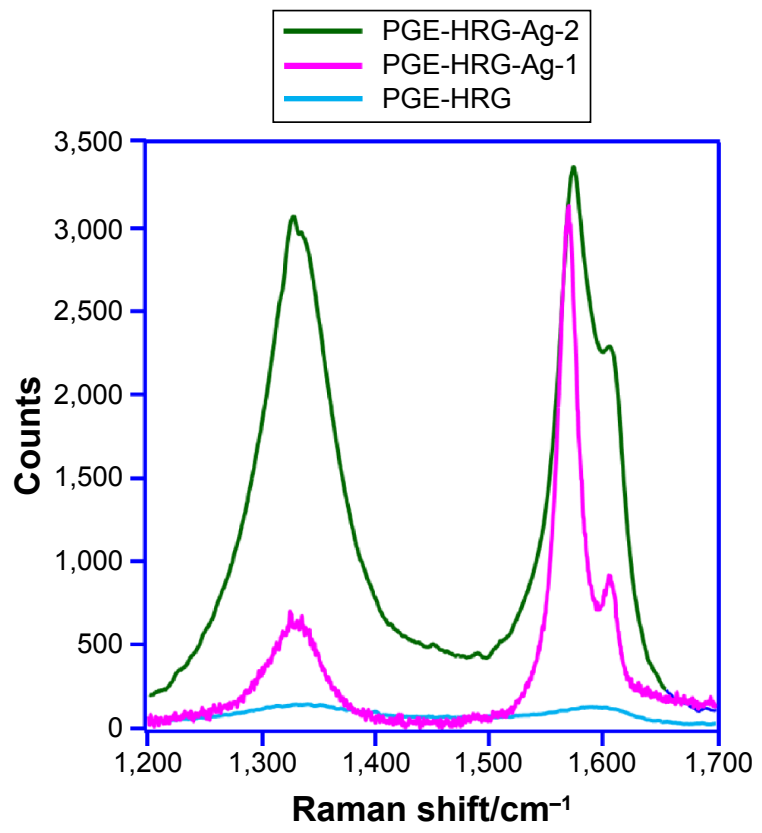

Figure 4 Raman spectra of graphene/silver nanocomposites with 50 wt\% (PGEHRG-Ag-I, pink line) and $100 w t \%$ (PGE-HRG-Ag-2, green line) of Ag NPs with respect to graphene and PGE-HRG without Ag NPs (blue line).

Notes: Increasing the concentration of Ag NPs, the intensities of the Raman signals also increase, which not only confirms the binding of the Ag NPs on the surface of graphene but also demonstrates the increased density of the Ag NPs.

Abbreviation: NPs, nanoparticles. correspond to the $\mathrm{G}$ and $\mathrm{D}$ bands, respectively, also appeared at a similar position with weak intensities in PGE-HRG-Ag. However, the intensities of these signals were significantly enhanced by the incorporation of Ag NPs, which confirms the binding of silver NPs to the surface of graphene. Moreover, the transmission electron microscopy images of the nanocomposites PGE-HRG-Ag-1 and - 2 clearly indicated that the Ag NP density can be amplified by increasing the amount of $\mathrm{AgNO}_{3}$ and the particle size distribution was found to be more uniform for higher concentrations (Figure 5).

\section{Anticancer activity}

Apoptosis is a form of cell death in which a programmed sequence of events eliminates cells without damaging the neighboring cells. Apoptosis performs a key role in sustaining normal tissue homeostasis by regulating the balance between cell proliferation and cell death. ${ }^{46}$ The design and development of new molecules that can induce apoptosis in cancer cells is an attractive approach for the treatment of cancer. The potential biomedical applications of graphene and graphenebased nanocomposites, such as graphene/silver nanocomposites, have been exploited for several applications, including antibacterial agents and nanocarriers for controlled loading and targeted delivery of anticancer drugs. However, the anticancer properties of graphene based-inorganic NP nanocomposites have been rarely tested, such as the one reported by Gurunathan et a ${ }^{47}$ wherein, they have reportedly used rGO-Ag nanocomposite against human ovarian cancer cells A2780. Hence, in this study, newly synthesized nanocomposites (PGE-HRG-Ag-1 and PGE-HRG-Ag-2) were evaluated for anticancer activity and their apoptosis inducing ability. 

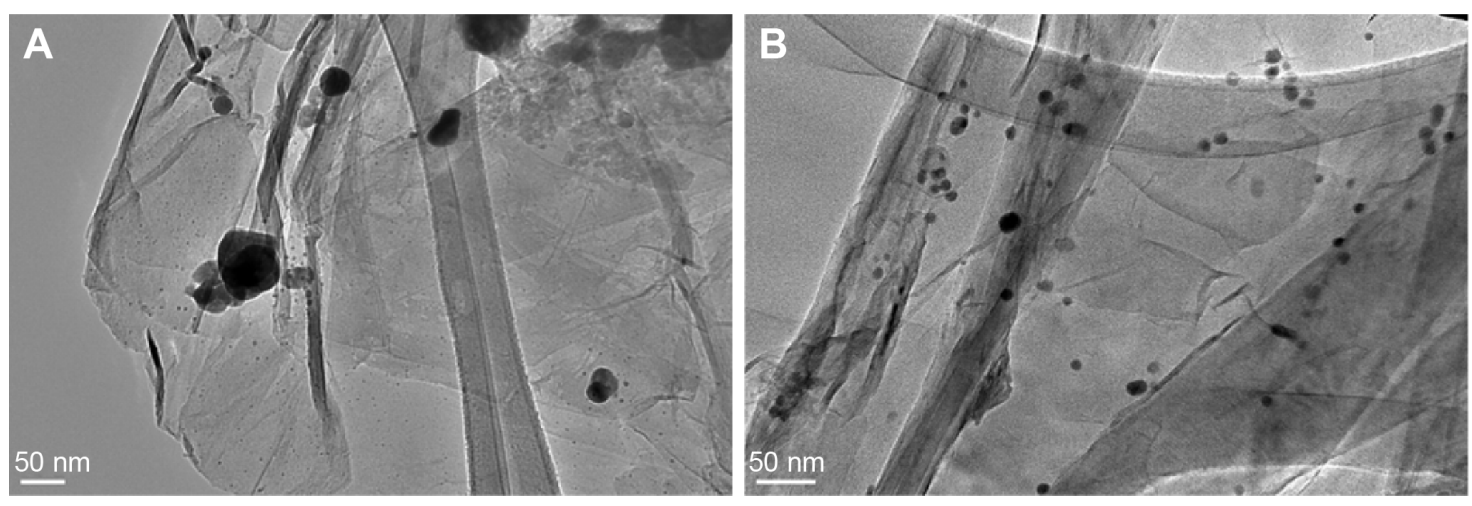

Figure 5 High resolution TEM images of (A) PGE-HRG-Ag-I and (B) PGE-HRG-Ag-2 prepared using 0.5 and I mmol of AgNO , respectively. Abbreviation: TEM, transmission electron microscopy.

The as prepared nanocomposites (PGE-HRG-Ag-1 and PGE-HRG-Ag-2) with varying concentration of Ag NPs were evaluated for their anticancer activity in a panel of five human cancer cell lines, namely MCF-7 (breast), A549 (lung), Hela (cervical), DU-145 (prostate) and HepG2 (liver) by using MTT method, ${ }^{41}$ and Tamoxifen was used as the reference drug. The results are given in Table 1 and expressed as $\mathrm{IC}_{50}$ values. The results exhibited that these nanocomposites demonstrate promising anticancer activity against the tested cell lines and PGE-HRG-Ag-2 exhibited more potent activity than standard tamoxifen against the human lung cancer cell line, $\mathrm{A} 549$, with an $\mathrm{IC}_{50}$ value of $9.63 \mu \mathrm{g}$. Therefore, A549 was selected as a model cell line for subsequent experiments.

\section{Cell cycle analysis}

Several anticancer compounds demonstrate their growth inhibitory effect either by arresting the cell cycle at a specific checkpoint of cell cycle or by induction of apoptosis or a collective effect of both cycle block and apoptosis. ${ }^{48,49}$ The in vitro screening results exhibited that the nanocomposite PGE-HRG-Ag-2 showed significant activity against the human lung cancer cell line, A549. Therefore, it was considered of interest to understand whether this inhibition of cell growth was on account of cell cycle arrest or induction

Table 2 FACS analysis in A549 human lung cancer cell line after treatment with PGE-HRG-Ag-2

\begin{tabular}{lllll}
\hline Sample & $\begin{array}{l}\text { Sub-GI } \\
(\%)\end{array}$ & $\begin{array}{l}\text { G0/G I } \\
(\%)\end{array}$ & $\begin{array}{l}\text { S } \\
\text { (\%) }\end{array}$ & $\begin{array}{l}\text { G2/M } \\
\text { (\%) }\end{array}$ \\
\hline A: Control (A549) & 8.42 & 81.32 & 2.78 & 6.46 \\
B: PGE-HRG-Ag-2 (5 $\mu \mathrm{g})$ & 14.24 & 71.67 & 3.54 & 6.78 \\
C: PGE-HRG-Ag-2 $(10 \mu \mathrm{g})$ & 50.50 & 41.49 & 0.77 & 1.41 \\
\hline
\end{tabular}

Abbreviation: FACS, fluorescence-activated cell sorting. of apoptosis or both. Hence, in this study, A549 cells were treated with this nanocomposite at concentrations of 5 and $10 \mu \mathrm{g}$ for 48 hours. The data obtained clearly indicated that this nanocomposite arrested cell cycle at $\mathrm{G} 0 / \mathrm{G} 1$ phase. The values obtained are given in Table 2. Interestingly, when the concentration was increased from 5 to $10 \mu \mathrm{g}$, it was noticed that the percentage of cells in $\mathrm{G} 0 / \mathrm{G} 1$ phase was decreased and accumulation of cells in subG1 phase increased in a dose-dependent manner, which indicates the onset of apoptosis (Figure 6)..$^{50}$

\section{Measurement of $\Delta \Psi \mathrm{m}$}

Mitochondrial membrane potential $(\Delta \Psi \mathrm{m})$ plays significant role for mitochondrial integrity and bio energetic function. ${ }^{43}$ Mitochondrial changes, including loss of $\Delta \Psi \mathrm{m}$, are key events that take place during drug-induced apoptosis. Mitochondrial injury by PE-HRG-Ag-2 was evaluated by detecting drops in $\Delta \Psi \mathrm{m}$. In this experiment, we have investigated the involvement of mitochondria in the induction of apoptosis by PE-HRG-Ag-2. After 48 hours of drug treatment with this compound at 5 and $10 \mu \mathrm{g}$ concentrations, it was observed that there was a reduced $\Delta \Psi \mathrm{m}$ of A549 cells, assessed by JC-1 staining (Figure 7).

\section{Effect on intracellular ROS generation}

A number of anticancer compounds have been known to exert their anticancer effects by the generation of ROS, ${ }^{52,53}$ which is considered as one of the key mediators of apoptotic signaling. In this connection, nanocomposite PGE-HRG-Ag-2 was evaluated for its ROS-inducing capability in A549 cells. A549 cells were treated with this compound and stained with DCFDA for ROS measurement. After treatment with this nanocomposite at 5 and $10 \mu \mathrm{g}$ concentrations for 48 hours, the level of ROS was significantly increased (Figure 8). The 

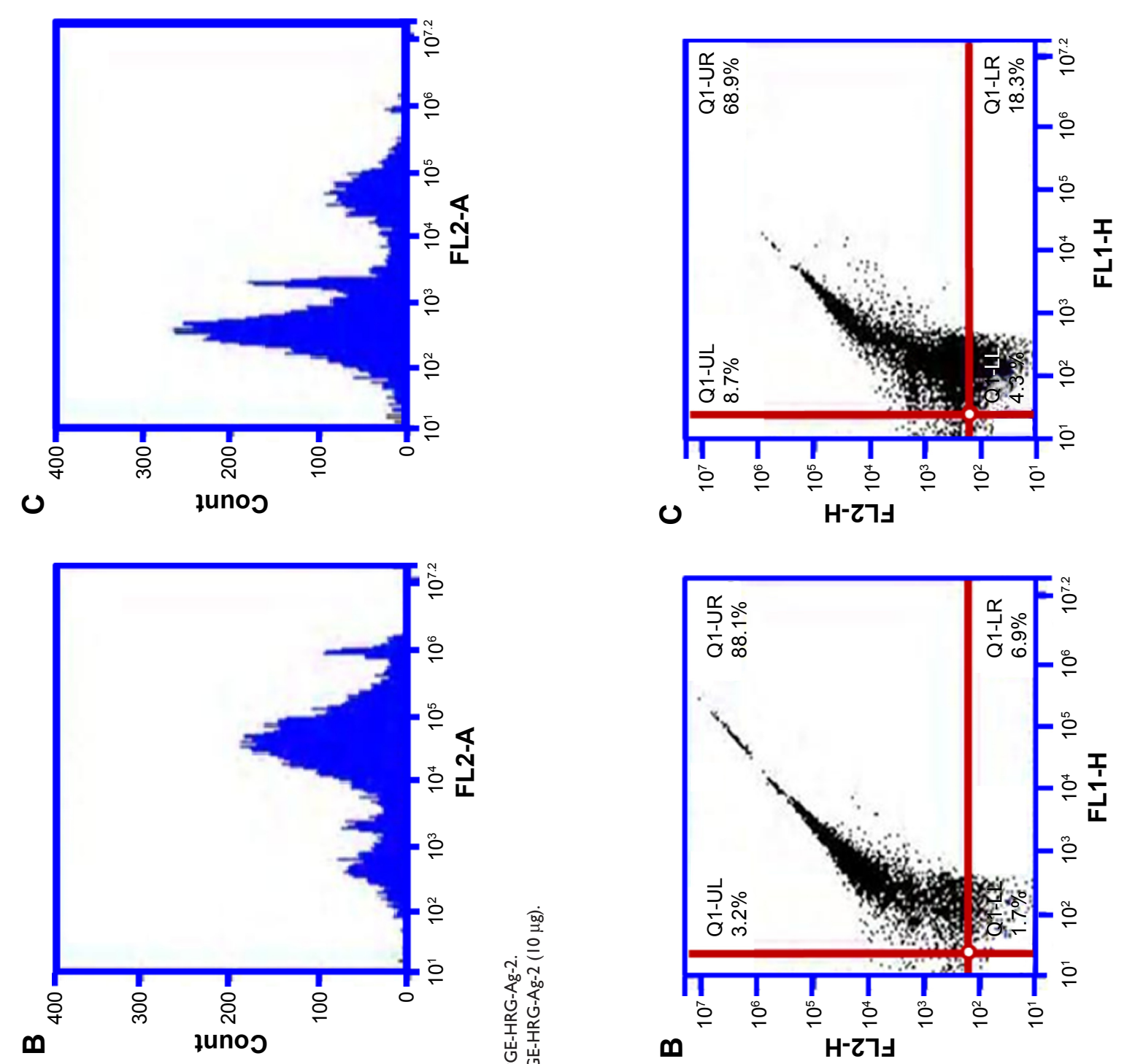

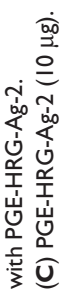
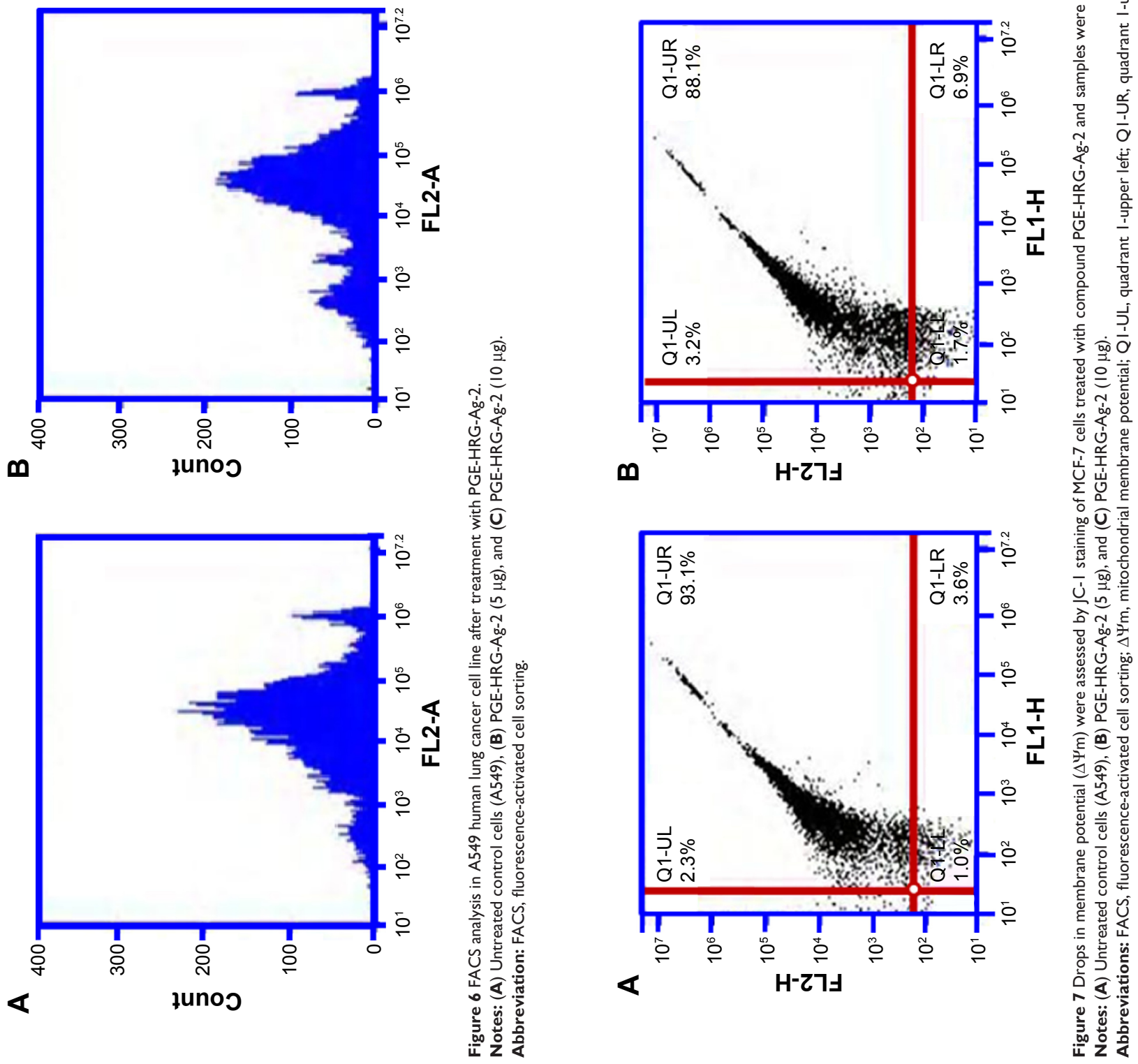


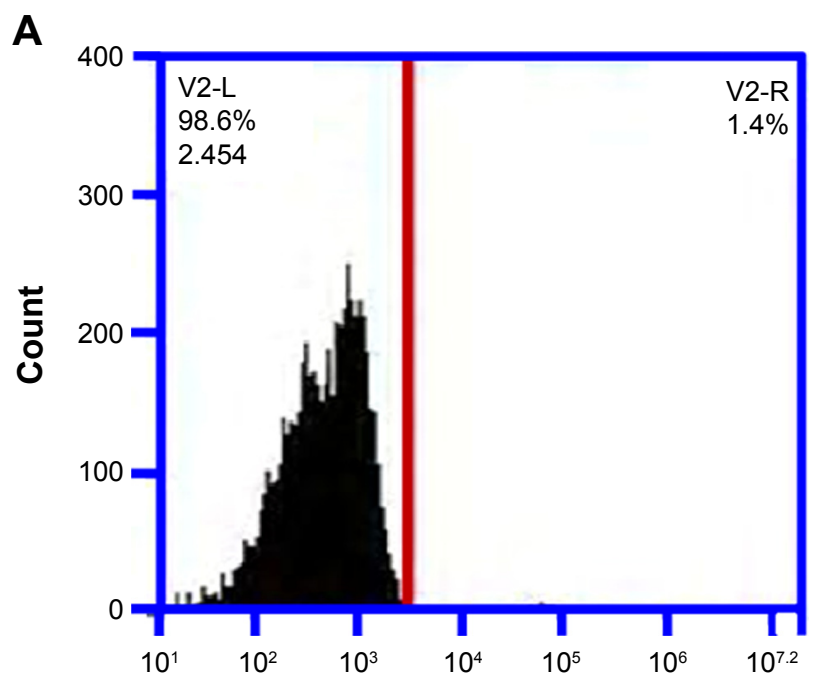

FL2-A

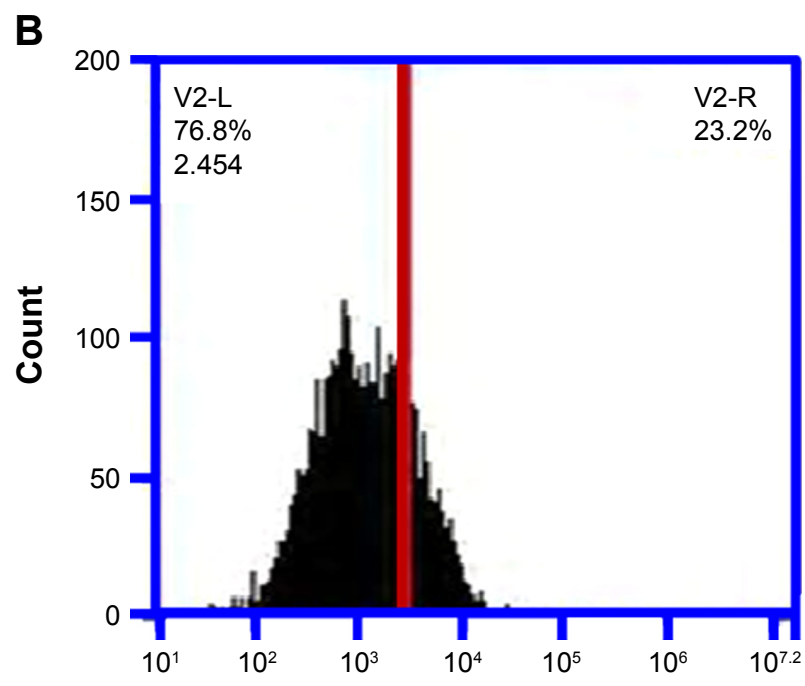

FL2-A

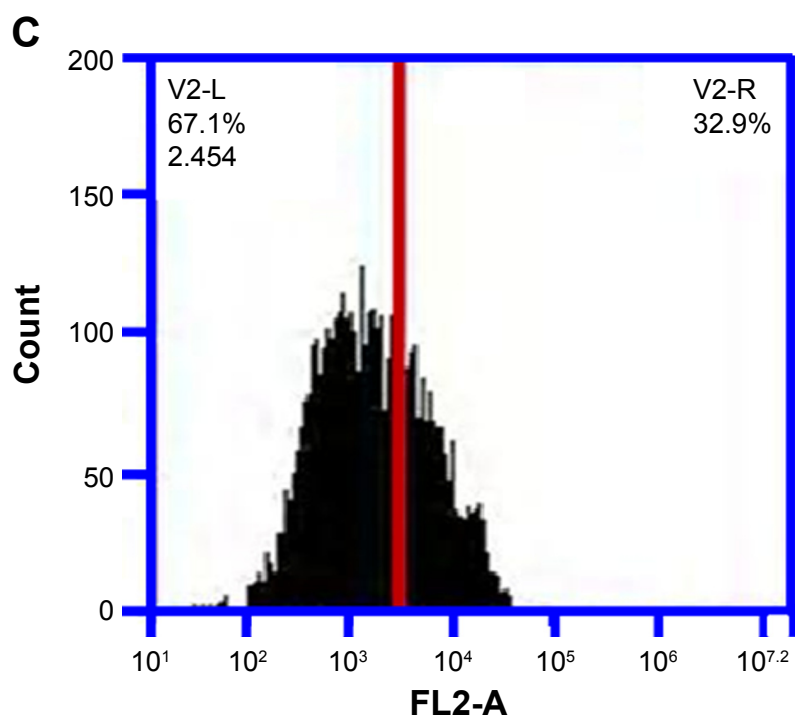

Figure 8 The effect of PGE-HRG-Ag-2 on the ROS production in human lung cancer (A549).

Notes: (A) Untreated control cells (A549), (B) PGE-HRG-Ag-2 (5 $\mu$ g), and (C) PGE-HRG-Ag-2 (10 $\mu \mathrm{g})$.

Abbreviation: ROS, reactive oxygen species.

ratio of DCF-positive cells for PGE-HRG-Ag-2 was 23.2\% and $32.9 \%$ at 5 and $10 \mu \mathrm{g}$ concentrations respectively, for 48 hours and the level of ROS was significantly increased (Figure 8). Hence, from the test results it can be concluded that the compounds tested had enhanced the generation of ROS in A549 cells.

Table 3 Data obtained from Annexin V-FITC staining assay

\begin{tabular}{|c|c|c|c|c|}
\hline Sample & UL (\%) & UR (\%) & LL (\%) & LR (\%) \\
\hline A: Control (A549) & 0.49 & 2.34 & 96.69 & 0.48 \\
\hline B: PGE-HRG-Ag-2 $(5 \mu g)$ & 1.61 & 10.31 & 86.23 & 1.85 \\
\hline C: PGE-HRG-Ag-2 $(10 \mu g)$ & 3.94 & 18.33 & 75.21 & 2.53 \\
\hline
\end{tabular}

Abbreviations: UL, necrotic cells; UR, late apoptotic cells; LL, live cells; LR, early apoptotic cells.

\section{Annexin V-FITC for apoptosis}

The apoptotic effect of compound PGE-HRG-Ag-2 was studied by Annexin V-FITC assay. ${ }^{54}$ In this study, A549 cells were treated with nanocomposite PGE-HRG-Ag-2 for 48 hours at 5 and $10 \mu \mathrm{g}$ concentrations to examine the apoptotic effect. Results, as shown in Table 3, suggest that this compound induced significant apoptosis in human lung cancer cells. A graphical representation of the data is given in Figure 9.

\section{Conclusion}

Development of anticancer agents that can induce apoptosis is an attractive target for cancer cure and treatment. In this study, we have investigated the anticancer property of green synthesized nanocomposites of silver decorated 

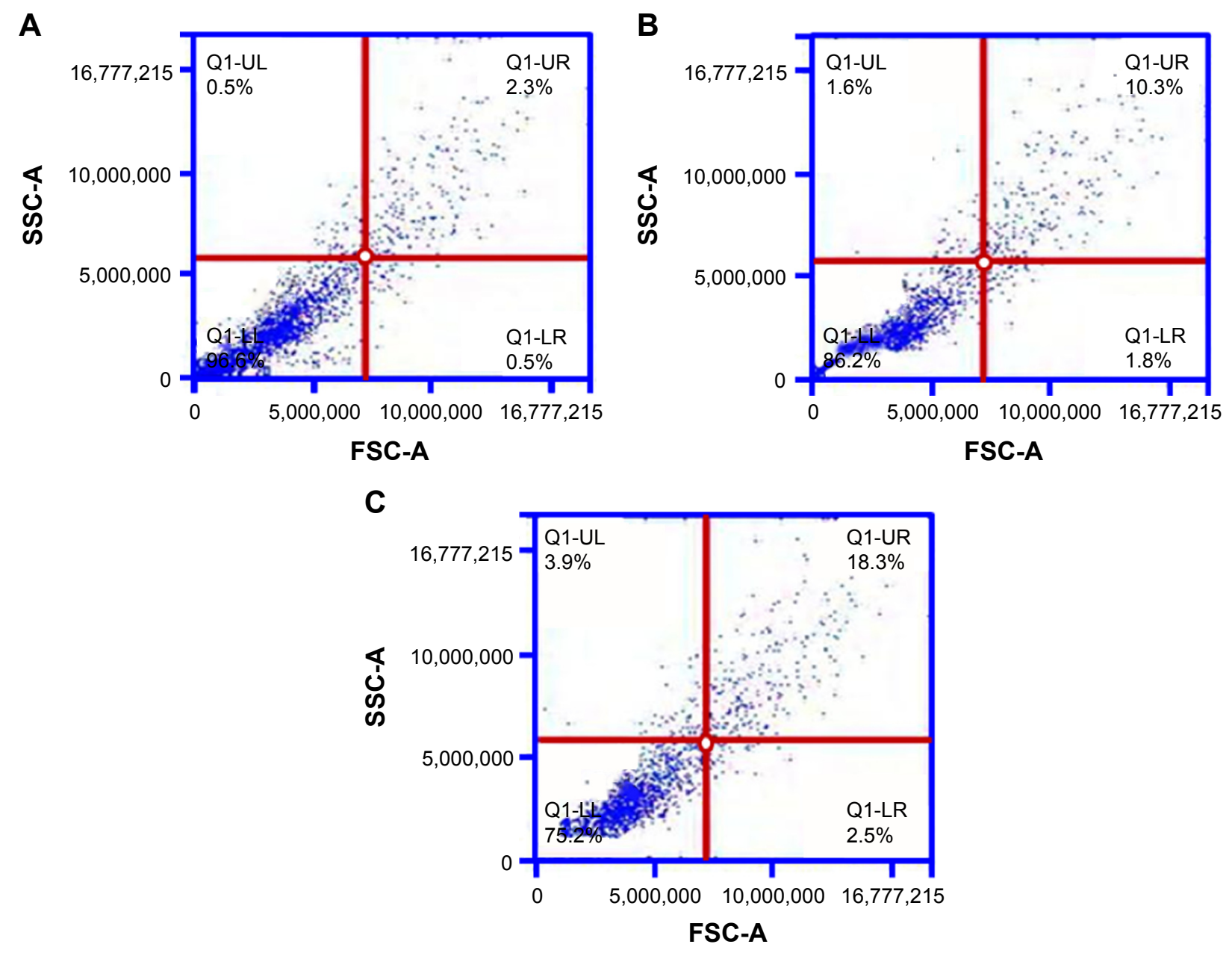

Figure 9 Annexin V-FITC staining.

Notes: (A) Untreated control cells (A549), (B) PGE-HRG-Ag-2 (5 $\mu$ g), and (C) PGE-HRG-Ag-2 (I0 $\mu$ g).

Abbreviations: QI-UL, quadrant I-upper Left; QI-UR, quadrant I-upper right; QI-LL, quadrant I-lower left; Q I-LR, quadrant I-lower right.

highly reduced graphene oxide (PGE-HRG-Ag-1 \& 2). Flow cytometry results suggested that this compound arrested the cell cycle at $\mathrm{G} 0 / \mathrm{G} 1$ phase at $5 \mu \mathrm{g}$ concentration. Interestingly, when the concentration was increased from 5 to $10 \mu \mathrm{g}$, it was observed that the percentage of cells in G0/G1 phase was decreased and accumulation of cells in subG1 phase increased in a dose-dependent manner, which indicates the onset of apoptosis. From the studies such as the measurement of $\triangle \Psi \mathrm{m}$, generation of ROS, and Annexin V-FITC assay it can be concluded that the tested compound induced cell death by apoptosis and PGE-HRG-Ag-2 was found to be the most potent in inducing cell death by apoptosis against human lung cancer cells, A549.

\section{Acknowledgment}

This project was supported by King Saud University, Deanship of Scientific Research, College of Science, Research Centre.

\section{Disclosure}

The authors report no conflicts of interest in this work.

\section{References}

1. Piotto M, Saudek V, Sklenář V. Gradient-tailored excitation for singlequantum NMR spectroscopy of aqueous solutions. J Biomol NMR. 1992; 2(6):661-665.

2. Kaur K, Kumar V, Sharma AK, Gupta GK. Isoxazoline containing natural products as anticancer agents: a review. Eur J Med Chem. 2014; 77:121-133.

3. Newman DJ, Cragg GM. Natural products as sources of new drugs over the last 25 years. J Nat Prod. 2007;70(3):461-477.

4. Weder JE, Dillon CT, Hambley TW, et al. Copper complexes of nonsteroidal anti-inflammatory drugs: an opportunity yet to be realized. Coord Chem Rev. 2002;232(1):95-126.

5. Neelam B, Fehmida N, Alok B, Sudha B, Amir A. Palladium (II) complexes of NS donor ligands derived from S-methyl-dithiocarbazate, S-benzyldithiocarbazate and thiosemicarbazide as antiamoebic agents. Eur J Med Chem. 2000;35(5):481-486.

6. Hawksworth EL, Andrews PC, Lie W, Lai B, Dillon CT. Biological evaluation of bismuth non-steroidal anti-inflammatory drugs (BiNSAIDs): Stability, toxicity and uptake in HCT-8 colon cancer cells. $J$ Inorg Biochem. 2014;135:28-39. 
7. Mendes IC, Moreira JP, Mangrich AS, Balena SP, Rodrigues BL, Beraldo H. Coordination to copper (II) strongly enhances the in vitro antimicrobial activity of pyridine-derived N (4)-tolyl thiosemicarbazones. Polyhedron. 2007;26(13):3263-3270.

8. Sekhon B, Gandhi L. Medicinal uses of inorganic compounds-1. Resonance. 2006;11(4):75-89.

9. Chen J, Peng H, Wang X, Shao F, Yuan Z, Han H. Graphene oxide exhibits broad-spectrum antimicrobial activity against bacterial phytopathogens and fungal conidia by intertwining and membrane perturbation. Nanoscale. 2014;6(3):1879-1889.

10. Li J, Wang G, Zhu H, et al. Antibacterial activity of large-area monolayer graphene film manipulated by charge transfer. Sci Rep. 2014;4:4359.

11. Zhao J, Deng B, Lv M, et al. Graphene oxide-based antibacterial cotton fabrics. Adv Healthc Mater. 2013;2(9):1259-1266.

12. Yang $X$, Wang $Y$, Huang $X$, et al. Multi-functionalized graphene oxide based anticancer drug-carrier with dual-targeting function and $\mathrm{pH}-$ sensitivity. J Mat Chem. 2011;21(10):3448-3454.

13. Jiang T, Sun W, Zhu Q, et al. Furin-mediated sequential delivery of anticancer cytokine and small-molecule drug shuttled by graphene. $A d v$ Mater. 2015;27:1021-1028.

14. Liu C-W, Xiong F, Jia HZ, et al. Graphene-based anticancer nanosystem and its biosafety evaluation using a zebrafish model. Biomacromolecules. 2013;14(2):358-366.

15. Zhou T, Zhou X, Xing D. Controlled release of doxorubicin from graphene oxide based charge-reversal nanocarrier. Biomaterials. 2014;35(13): 4185-4194.

16. Wang Y, Polavarapu L, Liz-Marzán LM. Reduced graphene oxidesupported gold nanostars for improved SERS sensing and drug delivery. ACS Appl Mater Interfaces. 2014;6(24):21798-21805.

17. Shen $H$, Zhang L, Liu M, Zhang Z. Biomedical applications of graphene. Theranostics. 2012;2(3):283-294.

18. Wang S, Yang B, Zhang S, Yuan J, Si Y, Chen H. Mechanical properties and failure mechanisms of graphene under a central load. Chemphyschem. 2014;15(13):2749-2755.

19. Yang B, Wang S, Guo Y, et al. Strength and failure behavior of a graphene sheet containing bi-grain-boundaries. RSC Advances. 2014;4(97): 54677-54683.

20. Kholmanov IN, Magnuson CW, Aliev AE, et al. Improved electrical conductivity of graphene films integrated with metal nanowires. Nano Letters. 2012;12(11):5679-5683.

21. Li Z, Yang B, Zhang S, Zhao C. Graphene oxide with improved electrical conductivity for supercapacitor electrodes. Appl Surf Sci. 2012; 258(8):3726-3731.

22. Sankar KV, Selvan RK. Improved electrochemical performances of reduced graphene oxide based supercapacitor using redox additive electrolyte. Carbon. 2015;90:260-273.

23. Liu L, Xiao L, Zhang X, et al. Improvement of the thermal conductivity and friction performance of poly (ether ether ketone)/carbon fiber laminates by addition of graphene. RSC Adv. 2015;5(71):57853-57859.

24. Khan M, Tahir MN, Adil SF, et al. Graphene based metal and metal oxide nanocomposites: synthesis, properties and their applications. J Mater Chem A. 2015;3(37):18753-18808.

25. Alabbad S, Adil S, Assal M, Khan M, Alwarthan A, Siddiqui MRH. Gold \& silver nanoparticles supported on manganese oxide: Synthesis, characterization and catalytic studies for selective oxidation of benzyl alcohol. Arabian J Chem. 2014;7(6):1192-1198.

26. Adil SF, Alabbad S, Kuniyil M, et al. Vanadia supported on nickel manganese oxide nanocatalysts for the catalytic oxidation of aromatic alcohols. Nanoscale Res Lett. 2015;10(1):52.

27. Khan M, Al-Marri AH, Khan M, et al. Pulicaria glutinosa plant extract: a green and eco-friendly reducing agent for the preparation of highly reduced graphene oxide. RSC Adv. 2014;4(46):24119-24125.

28. Dutta S, Ray C, Sarkar S, Pradhan M, Negishi Y, Pal T. Silver nanoparticle decorated reduced graphene oxide (rGO) nanosheet: a platform for SERS based low-level detection of uranyl ion. ACS Appl Mater Interfaces. 2013;5(17):8724-8732.
29. Adil SF, Assal ME, Khan M, Al-Warthan AA, Siddiqui MRH, LizMarzán LM. Biogenic synthesis of metallic nanoparticles and prospects toward green chemistry. Dalton Trans. 2015;44:9709-9717.

30. Dhillon GS, Brar SK, Kaur S, Verma M. Green approach for nanoparticle biosynthesis by fungi: current trends and applications. Crit Rev Biotechnol. 2012;32(1):49-73.

31. Hussain MA, Shah A, Jantan I, et al. One pot light assisted green synthesis, storage and antimicrobial activity of dextran stabilized silver nanoparticles. J Nanobiotechnol. 2014;12(1):53.

32. Iravani S. Green synthesis of metal nanoparticles using plants. Green Chem. 2011;13(10):2638-2650.

33. Al-Marri AH, Khan M, Khan M, et al. Pulicaria glutinosa extract: a toolbox to synthesize highly reduced graphene oxide-silver nanocomposites. Int J Mol Sci. 2015;16(1):1131-1142.

34. Kamal A, Shaik AB, Reddy GN, et al. Synthesis, biological evaluation, and molecular modeling of (E)-2-aryl-5-styryl-1, 3, 4-oxadiazole derivatives as acetylcholine esterase inhibitors. Med Chem Res. 2014; 23(4):2080-2092.

35. Kamal A, Tamboli JR, Vishnuvardhan M, Adil S, Nayak VL, Ramakrishna S. Synthesis and anticancer activity of heteroaromatic linked $4 \beta$-amido podophyllotoxins as apoptotic inducing agents. Bioorg Med Chem Lett. 2013;23(1):273-280.

36. Kamal A, Ashraf M, Vardhan MV, Faazil S, Nayak VL. Synthesis and anticancer potential of benzothiazole linked phenylpyridopyrimidinones and their diones as mitochondrial apoptotic inducers. Bioorg Med Chem Lett. 2014;24(1):147-151.

37. Kamal A, Tamboli JR, Nayak VL, Adil S, Vishnuvardhan M, Ramakrishna S. Synthesis of pyrazolo [1,5-a] pyrimidine linked aminobenzothiazole conjugates as potential anticancer agents. Bioorg Med Chem Lett. 2013;23(11):3208-3215.

38. Khan M, Khan M, Kuniyil M, et al. Biogenic synthesis of palladium nanoparticles using Pulicaria glutinosa extract and their catalytic activity towards the Suzuki coupling reaction. Dalton Trans. 2014;43(24): 9026-9031.

39. Ji L, Tan Z, Kuykendall TR, et al. $\mathrm{Fe}_{3} \mathrm{O}_{4}$ nanoparticle-integrated graphene sheets for high-performance half and full lithium ion cells. Phys Chem Chem Phys. 2011;13(15):7170-7177.

40. Hummers WS, Offeman RE. Preparation of graphitic oxide. J Am Chem Soc. 1958;80(6):1339-1339.

41. Botta M, Armaroli S, Castagnolo D, Fontana G, Pera P, Bombardelli E. Synthesis and biological evaluation of new taxoids derived from 2-deacetoxytaxinine J. Bioorg Med Chem Lett. 2007;17(6): 1579-1583.

42. Szumilak M, Szulawska-Mroczek A, Koprowska K, et al. Synthesis and in vitro biological evaluation of new polyamine conjugates as potential anticancer drugs. Euro J Med Chem. 2010;45(12):5744-5751.

43. Chakravarti B, Maurya R, Siddiqui JA, et al. In vitro anti-breast cancer activity of ethanolic extract of Wrightia tomentosa: role of proapoptotic effects of oleanolic acid and urosolic acid. JEthnopharmacol. 2012;142(1):72-79.

44. Ding G, Liu F, Yang T, Jiang Y, Fu H, Zhao Y. A novel kind of nitrogen heterocycle compound induces apoptosis of human chronic myelogenous leukemia K562 cells. Bioorg Med Chem. 2006;14(11): 3766-3774.

45. Browne L, Gude C, Rodriguez H, Steele R, Bhatnager A. Fadrozole hydrochloride: a potent, selective, nonsteroidal inhibitor of aromatase for the treatment of estrogen-dependent disease. J Med Chem. 1991;34(2): $725-736$.

46. Evan GI, Vousden KH. Proliferation, cell cycle and apoptosis in cancer. Nature. 2001;411(6835):342-348.

47. Gurunathan S, Han JW, Park JH, et al. Reduced graphene oxide-silver nanoparticle nanocomposite: a potential anticancer nanotherapy. Int J Nanomedicine. 2015;10:6257.

48. Shen J-K, Du H-p, Yang M, Wang Y-G, Jin J. Casticin induces leukemic cell death through apoptosis and mitotic catastrophe. Ann Hematol. 2009;88(8):743-752. 
49. Chan KT, Meng FY, Li Q, et al. Cucurbitacin B induces apoptosis and $\mathrm{S}$ phase cell cycle arrest in BEL-7402 human hepatocellular carcinoma cells and is effective via oral administration. Cancer Lett. 2010; 294(1):118-124.

50. Hotz MA, Gong J, Traganos F, Darzynkiewicz Z. Flow cytometric detection of apoptosis: comparison of the assays of in situ DNA degradation and chromatin changes. Cytometry. 1994;15(3): 237-244.

51. Gonda K, Tsuchiya H, Sakabe T, et al. Synthetic retinoid CD437 induces mitochondria-mediated apoptosis in hepatocellular carcinoma cells. Biochem Biophys Res Commun. 2008;370(4):629-633.
52. Liu K, Zhang D, Chojnacki J, et al. Design and biological characterization of hybrid compounds of curcumin and thalidomide for multiple myeloma. Org Biomol Chem. 2013;11(29):4757-4763.

53. Sánchez Y, Simón GP, Calviño E, de Blas E, Aller P. Curcumin stimulates reactive oxygen species production and potentiates apoptosis induction by the antitumor drugs arsenic trioxide and lonidamine in human myeloid leukemia cell lines. J Pharmacol Exp Ther. 2010;335(1): $114-123$.

54. Zhu H, Zhang J, Xue N, Hu Y, Yang B, He Q. Novel combretastatin A-4 derivative XN0502 induces cell cycle arrest and apoptosis in A549 cells. Invest New Drugs. 2010;28(4):493-501.
International Journal of Nanomedicine

\section{Publish your work in this journal}

The International Journal of Nanomedicine is an international, peerreviewed journal focusing on the application of nanotechnology in diagnostics, therapeutics, and drug delivery systems throughout the biomedical field. This journal is indexed on PubMed Central, MedLine, CAS, SciSearch $®$, Current Contents $\AA /$ Clinical Medicine,

\section{Dovepress}

Journal Citation Reports/Science Edition, EMBase, Scopus and the Elsevier Bibliographic databases. The manuscript management system is completely online and includes a very quick and fair peer-review system, which is all easy to use. Visit http://www.dovepress.com/ testimonials.php to read real quotes from published authors.

Submit your manuscript here: http://www.dovepress.com/international-journal-of-nanomedicine-journal 